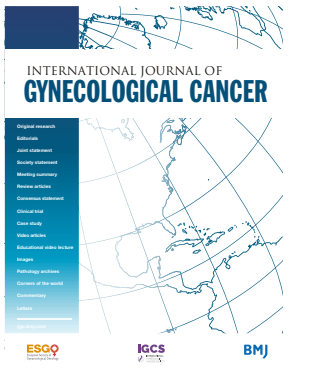

${ }^{1}$ Obstetrics and Gynecology, Clinica Universidad de Navarra, Madrid, Spain

${ }^{2}$ Thoracic Surgery, Clinica Spain

Correspondence to Dr Felix Boria, Clinica Universidad de Navarra Departamento de Ginecologia y Obstetricia, Madrid 28027, Spain; f.boria.alegre@gmail. com

Accepted 16 March 2021 Published Online First 1 April 2021 Universidad de Navarra, Madrid,

\section{Thoracic anatomical landmarks and uniportal VATS cardiophrenic lymph node resection in advanced ovarian cancer}

Felix Boria (1) ," Maria Rodriguez-Perez, ${ }^{2}$ Daniel Vázquez-Vicente (D) ," Teresa Castellanos, ${ }^{1}$ Enrique Chacon (D) ${ }^{1}$ Luis Chiva (D) ${ }^{1}$
Thoracic anatomical landmarks and uniportal videoassisted thoracoscopic surgery (VATS) cardiophrenic lymph node resection in advanced ovarian cancer.

VATS represents a useful approach in advanced ovarian cancer. Its main indications are pleural assessment when a pleural effusion is present and cytoreductive surgery in resectable metastatic disease (such as cardiophrenic lymph node metastases). ${ }^{1}$ Enlarged cardiophrenic lymph nodes are associated with a poor prognosis. Although no studies to date had shown a benefit of its removal in overall survival or progression-free survival, as we show, it is a feasible technique. ${ }^{2}$ Cardiophrenic lymph node resection can be achieved by transdiaphragmatic, transxiphoid, ${ }^{3}$ or a transthoracic approach by VATS. The uniportal video-assisted thoracoscopic surgery (UVATS) is considered the evolution of conventional three-port VATS, with even less morbidity and faster recovery. ${ }^{4}$

This video article shows some tips and tricks for uniportal VATS and the essential anatomical landmarks that we should know before performing it. Then, we demonstrate how to perform a cardiophrenic lymph node resection by uniportal VATS.
For this technique, a double-lumen tube endotracheal anesthesia is recommended, although tubeless thoracic surgery may be an option in some selected cases.

The patient is positioned in a full lateral decubitus position with the operation table flexed. Adequate triangulation with the lesion location must be achieved. Then, a $2 \mathrm{~cm}$ incision is made in the upper border of the rib. Attention must be paid to spare and not cut the thoracic wall muscles, as the latissimus dorsii or the serratus anterior.

This incision serves to place the camera and to introduce the working instruments. An extra-small alexys-type wound retractor can be used to facilitate the surgical maneuvers.

Once the incision is done, an assistant manages the camera while the first surgeon performs the resection with an advanced sealing device and curved ring forceps.

Once the surgery is finished, we will evacuate the pneumothorax placing a small catheter through the incision and into a $2 \mathrm{~cm}$ custom-made water seal. If it fails, a 24-Fr chest tube would be placed through
Check for updates

(C) IGCS and ESG0 2021. No commercial re-use. See rights and permissions. Published by BMJ.

To cite: Boria F,

Rodriguez-Perez $\mathrm{M}$,

Vázquez-Vicente $\mathrm{D}$, et al. Int $\mathrm{J}$ Gynecol Cancer 2021;31:793794.

\section{INTERNATIONAL IOURNAL OF GYNECOLOGICAL CANCER}

Thoracic anatomical landmarks and uniportal VATS cardiophrenic lymph node resection in advanced ovarian cancer
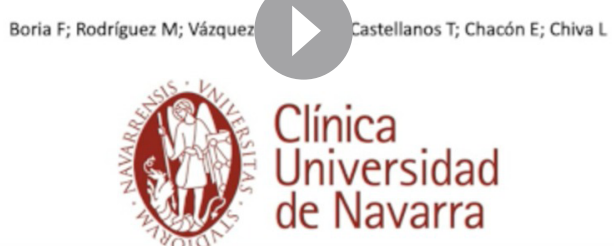
Clínica Universidad de Navarra
@ugConline
Video 1 VATS cardiophrenic lymph node resection. 


\section{Video article}

the port incision. If not, the thorax is closed without any chest drain in it.

Twitter Felix Boria @BoriaFelix and Enrique Chacon @Quique_ChC

Contributors All authors contributed to the design and creation of the video.

Funding The authors have not declared a specific grant for this research from any funding agency in the public, commercial, or not-for-profit sectors.

Competing interests None declared.

Patient consent for publication Not required.

Provenance and peer review Not commissioned; externally peer reviewed.

Data availability statement There are no data in this work.

ORCID iDs

Felix Boria http://orcid.org/0000-0002-4761-6190
Daniel Vázquez-Vicente http://orcid.org/0000-0002-9618-5606

Enrique Chacon http://orcid.org/0000-0001-8659-8602

Luis Chiva http://orcid.org/0000-0002-1908-3251

\section{REFERENCES}

1 Di Guilmi J, Salvo G, Mehran R, et al. Role of video-assisted thoracoscopy in advanced ovarian cancer: a literature review. Int $J$ Gynecol Cancer 2016;26:801-6.

2 Boria F, Chiva L. Role of cardiophrenic lymph node removal in advanced ovarian cancer. Int J Gynecol Cancer 2021;31:307.

3 Martínez-Gómez C, Angeles MA, Leray H, et al. Transdiaphragmatic and transxiphoid cardiophrenic lymph node resection step-by-step in advanced ovarian cancer. Int J Gynecol Cancer 2020;30:1646-7.

4 Gonzalez D, Paradela M, Garcia J, et al. Single-port video-assisted thoracoscopic lobectomy. Interact Cardiovasc Thorac Surg 2011;12:514-5. 